STUDI

FRANCESI

\section{Studi Francesi}

Rivista quadrimestrale fondata da Franco Simone

$148(X L X \mid I) \mid 2006$

Varia - fasc. I - gennaio-aprile 2006

\title{
Des nouvelles d'Algérie, 1974-2004, sélectionnées et présentées par Christiane Chaulet Achour
}

\section{Paola Martini}

\section{(2) OpenEdition}

12 Journals

\section{Edizione digitale}

URL: http://journals.openedition.org/studifrancesi/30897

DOI: 10.4000/studifrancesi.30897

ISSN: 2421-5856

\section{Editore}

Rosenberg \& Sellier

\section{Edizione cartacea}

Data di pubblicazione: 1 avril 2006

Paginazione: 201

ISSN: 0039-2944

\section{Notizia bibliografica digitale}

Paola Martini, «Des nouvelles d'Algérie, 1974-2004, sélectionnées et présentées par Christiane Chaulet Achour», Studi Francesi [Online], 148 (XLX | I) | 2006, online dal 30 novembre 2015, consultato il 18 avril 2021. URL: http://journals.openedition.org/studifrancesi/30897 ; DOI: https://doi.org/10.4000/

studifrancesi.30897 


\title{
Des nouvelles d'Algérie, 1974-2004, sélectionnées et présentées par Christiane Chaulet Achour
}

\author{
Paola Martini
}

\section{NOTIZIA}

Des nouvelles d'Algérie, 1974-2004, sélectionnées et présentées par Christiane CHAULET ACHOUR, Paris, Éditions Métailié, 2005, pp. 346.

1 L'antologia curata da Christiane Chaulet Achour raccoglie venticinque novelle tratte dal vasto patrimonio letterario contemporaneo dell'Algeria. I tre decenni presi in considerazione, dal 1974 al 2004, sono quelli in cui si sono verificati i maggiori cambiamenti sia a livello della società civile che del potere politico. A partire dagli anni Settanta ha avuto luogo una lenta e progressiva emancipazione del settore dell'editoria dal controllo dello stato e un conseguente incremento della produzione letteraria che è riuscita, non senza sforzi e difficoltà, a dar voce ai problemi e ai malesseri della moderna società algerina.

2 Nella raccolta compaiono i nomi di venti scrittori e di cinque scrittrici le cui novelle sono precedute da una bio-bibliografia essenziale. Mancano tuttavia nomi importanti del panorama letterario algerino come, per esempio, quello di Malek Haddad e di Mouloud Feraoun, perché la data di pubblicazione delle loro opere non coincideva con il trentennio selezionato dalla curatrice del volume. Salta agli occhi anche l'assenza di un classico come Kateb Yacine, che nel periodo al quale è dedicata la raccolta limita la propria produzione esclusivamente al teatro. Nella scelta delle opere la curatrice ha tenuto conto delle tre lingue parlate e scritte in Algeria - il francese, l'arabo e il dialetto della Cabilia - in modo da evidenziare la complessità e la ricchezza linguistica del paese. 
3 La miscellanea trova la sua coerenza nella scelta, del genere, la novella, riscoperta nel Novecento e con il quale la cultura maghrebina ha una speciale familiarità. Il racconto breve, traendo spunto da un fatto di cronaca, dalla finzione o da vicende autobiografiche, spiega Christiane Chaulet Achour, è in grado di svelare retroscena politici e di esplorare le relazioni umane; consente inoltre, per la sua incisività, di dire e di scrivere «dans l'instant et dans l'émotion» (p.15). I percorsi di lettura da poter intraprendere sono molteplici - ad un punto di vista che prende in esame l'asse cronologico è possibile, ad esempio, affiancare un'indagine a carattere biografico - e tutti molto fruttuosi. 